\title{
Study on the professional level of nursing staff under the background of medical and nursing integration
}

\author{
Ruan Mingyang ${ }^{1}$, Tian Wenwen ${ }^{2}$ \\ ${ }^{1}$ Kunming University, Kunming 650214, China; \\ ${ }^{2}$ The First People's Hospital of Yunnan Province,Kunming,650032,China
}

\begin{abstract}
Keywords: medical and nursing combination; pension care; medical level; supply and demand status; aging
\end{abstract}

\begin{abstract}
Through the study found that the academic circles generally believe that, in terms of China's aging situation, family changes, the actual needs of the elderly, medical and nursing combination is imperative. Based on this, medical support combined with the connotation and the nursing staff demand and supply situation, the status quo of professional level of nursing staff and the existing problems are analyzed in the study, the analysis found that the nursing staff number in our country the gap is bigger, from the medical professional level and overall quality is also a big problem. Finally, combined with the analysis of graduate students, the Countermeasures of promoting the professional level of nursing staff under the background of medical and nursing integration has been put forward in this paper, which provides a valuable reference for improving the level of nursing service for the aged in china.
\end{abstract}

\section{Introduction}

At present in our country, whether the medical industry or the pension industry, lack of professional talents has become the main factor that restricts the development of the current employees pension institutions in China, the quality of employees is not high, ability has been unable to meet the diverse needs of elderly population is increasing in length, there is a problem of serious imbalance between supply and demand the. Therefore in the medical support combined with background, should increase the nursing staff training, improve the overall quality of nursing staff, but only by training is not able to drive the development of the pension industry, because even if the nursing staff has been related to training, but because the industry attraction is low, the nursing staff training may not be engaged in the industry also brings difficulties to the development of the industry. In order to improve the service level of the pension institutions, it is of great practical significance to study the nursing staff for the aged.

\section{Connotation of medical and nursing integration and status quo of supply and demand of nursing staff}

At present, the main problem restricting the development of the pension industry in China is the lack of talents. Under the background of the combination of medical care and nursing, this problem is more prominent

(1) Connotation of medical and nursing integration

The combination of medical care and health care refers to the integration of medical resources into the pension field, which can improve the endowment level of the pension structure, and is a concrete measure to meet the diverse needs of the elderly. In the combination of medical care background, hospitals, community health, pension institutions and pension service center should 
actively provide medical services for the aged, which requires nursing staff has certain medical skills with high quality and professional level, but in China, the emergence of the nursing staff is not a long time.

(2) Overview of nursing staff for the aged

In our country, the nursing staff as a full-time occupation is not a long time, promulgated the "nursing member national occupation standard" in 2002, in order to carry out occupation of the nursing staff of nursing staff to define, become a formal occupation. With the development of the pension industry, the number of nursing staff are constantly increasing, but with the speeding up of aging in China, the nursing staff can not meet the market demand, and the endowment's professional quality level is not high, which seriously restricted the normal development of the nursing profession.

(3) Supply and demand status of nursing staff training

According to statistics, in China over 65 years old already accounted for more than $10 \%$ of the total number, and 60 years old in the most "survival", which puts forward higher challenge to the pension service system and. At present, the nursing staff in China has exceeded about 1000000, but occupation qualified personnel rarely, these numbers far can not meet the demand of pension institutions, not only in quantity, in the professional level, the basic medical quality of nursing staff also needs to be improved, the existing staff are common to older age, low education occupation training, a series of problems such as less.

\section{Study on the status quo and existing problems of professional level of nursing staff for the aged in China}

At present, the overall level of professional nursing staff in China is not high, the quality of their own culture factors in addition to the reasons and nursing staff concerned, with treatment and professional training and other factors, the number of pension institutions were investigated, such as the results shown in figure 1.

Table 1 The survey of professional level of nursing staff in China

\begin{tabular}{|c|c|c|c|}
\hline \multirow{2}{*}{ Nursing content } & \multicolumn{3}{|c|}{ Professional skills of nursing staff } \\
\cline { 2 - 4 } & $\begin{array}{c}\text { Fully mastered } \\
/ \%\end{array}$ & $\begin{array}{c}\text { Partial mastered } \\
/ \%\end{array}$ & $\begin{array}{c}\text { Not mastered } \\
/ \%\end{array}$ \\
\hline Transfusion nursing & 45.5 & 43.3 & 11.2 \\
\hline Intramuscular injection & 32.2 & 53.1 & 14.7 \\
\hline Vital signs measurement & 65.2 & 22.3 & 12.5 \\
\hline Oral medication care & 62.1 & 22.3 & 15.6 \\
\hline Nursing care of critically ill patients & 46.2 & 43.5 & 10.3 \\
\hline First-aid and resuscitation & 48.2 & 31.6 & 21.2 \\
\hline
\end{tabular}

As shown in Table 1, the survey results can be seen in many health care programs, nursing staff and most of the staff did not master the nursing professional knowledge or only grasp part of nursing knowledge, for study of demand as shown in table 2. 
Table 2 questionnaire of learning needs of nursing staff's professional skills

\begin{tabular}{|c|c|c|c|}
\hline \multicolumn{5}{|c|}{ Whether nurses need to study their professional skills } \\
\hline Comparative needs /\% & General needs/\% & Not really needed/\% & Unwanted/\% \\
\hline 43.2 & 11.3 & 23.1 & 22.4 \\
\hline 45.3 & 12.5 & 22.5 & 19.7 \\
\hline 46.2 & 13.8 & 21.2 & 18.8 \\
\hline 44.3 & 16.7 & 22.5 & 16.5 \\
\hline 41.2 & 11.2 & 21.2 & 26.4 \\
\hline 45.2 & 15.3 & 26.3 & 13.2 \\
\hline
\end{tabular}

As shown in Table 2, the survey shows whether the professional skills of nursing staff need to learn, it does not need the personnel only a few, most of the nursing staff require a certain degree of professional training, which needs accounted for the largest proportion. However, there are still many problems in the field of professional training, which are mainly manifested in the following three aspects.

(1) The cultural quality is low and the training is difficult

At present most of the nursing staff, or is the bottom of the public, including laid-off workers and rural migrant workers, the overall quality of the nursing staff is low, which has a high school diploma is very few, these people learn more slowly, the nursing professional training has brought greater difficulties.

(2) Low salary, can not attract high-quality talents

Work and treatment is an important reason that restricts the development of the overall quality of the nursing staff, nationwide, nursing staff is generally low, even in the big city, the nursing staff wages are also difficult to maintain life. Because of low wages and benefits, with high-quality personnel to choose this kind of industry is less, especially young people less and less because of the high quality personnel, while the treatment is lower, treatment is more low, high-quality staff is less, resulting in vicious spiral.

(3) The training mode is single and the specialization is not enough.

Single mode of training, the nursing staff training in the majority of domestic service companies, the training is limited to basic nursing skills, the occupation morals and professional medical knowledge training rarely, so don't get good training effect.

\section{Countermeasures of promoting the professional level of nursing staff under the background of medical and nursing integration}

In order to improve the overall professionalism of the elderly nursing staff, it is necessary to increase the training of the elderly nursing staff, and improve the quality of the elderly nursing staff from various aspects.

(1) Increase government support

The combination of medical care under the background of pension service industry needs the guidance of the government, but also a responsibility of the government, the relevant government departments should increase efforts to support the introduction of relevant preferential policies to increase the pension service investment, to achieve free training of nursing staff.

(2) Improve the occupational guidelines for the elderly nursing staff 
The development of certain professional level standards for nursing staff entry, the development of pension institutions from bad constraints within a certain range, supervise pension institutions professional training for nursing staff, so as to improve the professional level of nursing staff.

(3) Develop various modes of training

Single mode training mode can effectively improve the nursing staff's professional level, in addition to the government led development of various modes of training, market development to promote the training of nursing staff, the public welfare transition to the market.

(4) Strengthen supervision and management

For the training of nursing staff and institutions, government departments should intensify supervision and management, promote the training structure effectively for the nursing staff to provide professional knowledge and skills training, the nursing staff is able to certificates, so as to improve the nursing staff of the medical professional level.

\section{Conclusion}

Under the background of combination of medicine and nursing, in order to improve the level of medical and professional service pension institutions of our country, the connotation and the combination of medical care and nursing staff demand and supply situation, the status quo of professional level of nursing staff and the existing problems are analyzed in the paper, and the Countermeasures to improve the nursing staff's professional level has been put forward. In order to make the pension service industry to develop normally, the government is needed to make a reasonable guide to the industry, and improve the level of wages and benefits of the industry, making the industry more attractive, enthusiasm and high-quality talents to participate in the industry, so as to enhance industry vitality and development space, and ultimately improve the overall level of China's pension services.

\section{Acknowledgements}

The work was supported by the construction project of Yunnan society, frontier and ecological environment research from Innovation team of philosophy and Social Sciences in Yunnan.

\section{Reference}

[1] Research group of China Center for aging research. State of disability in urban and rural elderly [J]. Disability Research, No.2, (2011), p.11-16.

[2] Liang Deying. Deying university community health service center was established to support medical with the integration of the pension model of a Chinese teacher community daycare center as an example [J]. Contemporary Medicine, Vol.17(27), (2011), p.152-153.

[3] Dou Ying. Long term care for the elderly is an important way to solve the current employment problem [J]. Northwest Population Journal, Vol.34 (3), (2013), p.98-101.

[4] Sun Wenqian. Public hospital medical support combined feasibility study - Hefei city Binhu mode elderly hospital as an example [J]. Journal of Anhui Agriculture University (Social Science Edition), Vol.22 (5), (2013), p.69-70.

[5] Dai Qingkang. On medical and health services as Kang Kei Igawa the security right [J]. China Health Law, Vol.21 (6), (2013), p.22-25. 
[6] Shen Lianfa. Thinking about the combination of medical care and health care. [J] Journal of Disease Monitor \& Control, No.6, (2015).

[7] Wu Yushao, Wang Lili, Kong Wei, Dong Pengtao, Yang Xiaoqi, et al. Study on the development of China's pension institutions [J]. Scientific Research on Aging, No.8, (2015).

[8] Tong Lifang, Zhao Qinghua, Ding Fu, Xiao Mingzhao. Exploration and practice of long term care model of medical care combined with elderly care $[\mathrm{J}]$. Nursing research of China, No.4, (2015).

[9] Chen Zhuoyi, Chen Weiran. Current situation and Countermeasures of nursing staff construction in China [J]. Journal of Changsha Social Work College, No.12, (2009).

[10] Peng Hongyan, Liu Youhua, Deng Jingyun. The nursing staff pension services in Wuhan city and thinking of [J]. Medical Journal of Chinese People's Health, Vol.23, (2011).

[11] Xia Yusong. The reform of medical insurance system from the perspective of welfare economics[J]. Modern Business Trade Industry, Vol.13, (2009), p.47-48.

[12] Zhu Jihua. The development of public administration theory and the construction of service oriented government [J]. Party \& Government Forum, No.07, (2009), p.14-16.

[13] Wang Yuhuan. Qualification admission and work content of long term care providers under the background of aging [J]. Chinese Journal of Gerontology, Vol.33(5), (2013), p.2105-2107.

[14] Chen Yinan. Experience and Enlightenment of long term care reform in Wisconsin [J]. Social Security Studies, No.2, (2011), p.171-177.

[15] Li Jing. Development history of long term care in the United States and Its Enlightenment to China [J]. Nursing research of China, Vol.25 (12), (2011), p.3298-3299.

[16] Qin Kun. Characteristics and Enlightenment of elderly health security system in Australia [J]. Journal of Beijing Administrative College, No.6, (2012), p.98-101.

[17] Wei Xinglin. Advanced experience of extended care among the elderly at home and abroad [J]. Friend of Science Amateurs, No.6, (2013), p.119-120. 